\title{
Importance and Benefits of Open Access Journal
}

\section{Zhengjun Liu*}

Department of Automation Measurement and Control Engineering, Harbin Institute of Technology, China

\section{The Importance of Open Access in your Field}

In recent years, Open Access is the format of providing unlimited access via the Internet to peer-reviewed scholarly journal papers. It is also increasingly being provided to theses, such as scholarly monographs and book chapters. The articles in Open access journal can be obtained more quickly than the one in conventional journal. Moreover the manuscripts can be published fast for Open Access. The last but not least, the number published paper is not unrestricted generally, because the papers is published by electrical version without printed version.

\section{Highlight the OMICS Group Special Features}

The website (http://www.omicsonline.org/special-features.php) has been shown some Special features. The feature 'Language translation' is beneficial to advertise the papers on our journal. In my opinion, this feature is unique among Open Access Journals. As the supplement, a function, automatic checking the similarity between the manuscript and published paper can be employed, if it is possible. The function will help the authors, reviewers and editors to exam the novelty of the submitted paper. Alternatively, a related paper list can automatically be given in the website (http://www.omicsonline.org/) by using several keywords.
${ }^{*}$ Corresponding author: Department of Automation Measurement and Control Engineering, Harbin Institute of Technology, China, E-mail: zjliu@hit.edu.cn

Received February 09, 2012; Accepted February 21, 2012; Published February 23, 2012

Citation: Liu Z (2012) Importance and Benefits of Open Access Journal. J Adv Robot Automat 1:e103. doi:10.4172/2168-9695.1000e103

Copyright: (c) 2012 Liu Z. This is an open-access article distributed under the terms of the Creative Commons Attribution License, which permits unrestricted use, distribution, and reproduction in any medium, provided the original author and source are credited. 